OPEN ACCESS

Edited by:

Richard Seifman,

United Nations Educational, Scientific and Cultural Organization, Italy

Reviewed by:

Janko Jankovic,

University of Belgrade, Serbia

Rohini Roopnarine,

St George's University, Grenada

*Correspondence:

Laura C. Streichert

Icstreichert@gmail.com

Specialty section:

This article was submitted to

Public Health Education and

Promotion,

a section of the journal

Frontiers in Public Health

Received: 07 December 2021

Accepted: 14 January 2022

Published: 24 February 2022

Citation:

Streichert LC, Sepe LP, Jokelainen P, Stroud CM, Berezowski J and Del Rio

Vilas VJ (2022) Participation in One

Health Networks and Involvement in the COVID-19 Pandemic Response: A Global Study.

Front. Public Health 10:830893. doi: 10.3389/fpubh.2022.830893

\section{Participation in One Health Networks and Involvement in the COVID-19 Pandemic Response: A Global Study}

\author{
Laura C. Streichert ${ }^{1 *}$, Ludovico P. Sepe ${ }^{2}$, Pikka Jokelainen ${ }^{3}$, Cheryl M. Stroud ${ }^{1}$, \\ John Berezowski ${ }^{4}$ and Víctor J. Del Rio Vilas ${ }^{5}$ \\ ${ }^{1}$ One Health Commission, Apex, NC, United States, ${ }^{2}$ Department Biological Safety, German Federal Institute for Risk \\ Assessment (BfR), Berlin, Germany, ${ }^{3}$ Infectious Disease Preparedness, Statens Serum Institut, Copenhagen, Denmark, \\ ${ }^{4}$ Scotland's Rural College, Inverness, United Kingdom, ${ }^{5}$ World Health Organization, Regional Office for South-East Asia, \\ New Delhi, India
}

The COVID-19 pandemic exemplifies a One Health issue at the intersection of human, animal, and environmental health that requires collaboration across sectors to manage it successfully. The global One Health community includes professionals working in many different fields including human medicine, veterinary medicine, public health, ecosystem health, and, increasingly, social sciences. The aims of this cross-sectional study were to describe the involvement of the global One Health community in COVID-19 pandemic response activities. One Health networks (OHNs) have formed globally to serve professionals with common interests in collaborative approaches. We assessed the potential association between being part of an $\mathrm{OHN}$ and involvement in COVID-19 response activities. Data were collected in July-August 2020 using an online questionnaire that addressed work characteristics, perceived connection to OHNs, involvement in COVID-19 pandemic response activities, and barriers and facilitators to the involvement. The sample included 1,050 respondents from 94 countries across a range of organizations and work sectors including, but not restricted to, those typically associated with a One Health approach. Sixty-four percent of survey respondents indicated involvement in pandemic response activities. Being part of an $\mathrm{OHN}$ was positively associated with being involved in the COVID-19 response (odds ratio: 1.8, 95\% confidence interval: 1.3-2.4). Lack of opportunities was a commonly reported barrier to involvement globally, with lack of funding the largest barrier in the WHO African region. This insight into diverse workforce involvement in the pandemic helps fill a gap in the global health workforce and public health education literature. An expanded understanding of the perceived roles and value of $\mathrm{OHNs}$ can inform targeted interventions to improve public health education and workforce capacity to prepare for and respond to public health emergencies.

Keywords: SARS-CoV-2, One Health, network, multisectoral, pandemic response, capacity-building 


\section{INTRODUCTION}

The COVID-19 pandemic is a complex issue that has affected almost every aspect of life worldwide $(1,2)$. It has led to the mobilization of a public health workforce and to community engagement campaigns in diverse contexts around the globe. Managing the pandemic requires strategies that facilitate communication and coordinate action across sectors and disciplines. One Health is an operational framework that takes an integrated, multisectoral, and transdisciplinary perspective, with a focus on the links between animal, human, and environmental health systems (3). The COVID-19 pandemic is considered a One Health issue because of its complexity and the zoonotic nature of the coronavirus SARS-CoV-2 (4-6).

The need for a coordinated One Health approach to mitigate and address pandemic risks, including COVID-19, has been embraced by leading international policy organizations, including the Tripartite made up of the World Health Organization (WHO), the World Organisation for Animal Health (OIE), and the Food and Agriculture Organization of the United Nations (FAO) (7); the United Nations Environment Programme (UNEP) (8); the World Bank (9-11); and others (1214). The release of a working definition for One Health with joint Tripartite and UNEP support demonstrates the momentum for operationalizing coordinated One Health approaches at multiple levels in the international arena (3). While there has been extensive rhetoric supporting the One Health concept and approach during the current pandemic, the impact of One Health networks on the extent of multisectoral workforce response to the COVID-19 pandemic has not been investigated on a global scale.

The proof of concept for the utility of One Health has been demonstrated repeatedly during previous outbreaks of zoonotic diseases $(13,15-17)$. The key messages from One Health actions reported during COVID-19 include the importance of a supportive environment with shared resources, interdisciplinary engagement, and strategies for communication networks (18, 19). To perform effectively, professionals need to be armed with the knowledge and skills from their own discipline, and also to be motivated and able to bridge with others (20). Proficiency in competencies required for understanding and applying One Health concepts requires breaking down disciplinary and professional siloes to find areas of overlap and complementarity (21-24).

Worldwide, One Health networks (OHNs) play a role in operationalizing One Health by providing information sharing, professional development, and opportunities for collaboration across disciplines (25-27). In April 2020, the WHO Global Outreach and Response Network (GOARN), in partnership with the One Health Commission (OHC) and the One Health European Joint Programme (One Health EJP), issued a COVID19 Call to Action seeking experts in One Health to assist during the pandemic (28). The rapid response to the call from over 600 professionals working in anthropology, medicine, epidemiology, veterinary care, wildlife, public health, ecohealth, and other disciplines demonstrated the potential of OHNs to reach and mobilize a diverse workforce. It also highlighted the need for more research to evaluate the outcomes and impacts of OHNs.
While the application of One Health approaches has been evaluated in a number of contexts (29-31), there has been relatively little assessment of the impact of OHNs or factors that support workforce efforts to operationalize One Health $(19,32-34)$. The aims of this study were to describe the involvement of a cross-section of the global One Health community in the COVID-19 pandemic response, to discern the barriers and facilitators that influenced that involvement, and to elucidate any connection between being associated with an OHN and involvement in COVID-19 response activities. This is the first study to examine the reach and impact of OHNs as determined by primary data across multiple contexts and, therefore, has relevance for many different audiences, including the general public.

\section{MATERIALS AND METHODS \\ Study Design and Recruitment}

We conducted a questionnaire-based descriptive study and report the work and its results following the STROBE checklist for cross-sectional studies (35) (Supplementary Material 1). The questionnaire was administered using an online survey tool (Survey Monkey), with no restrictions to respondents. The survey link was distributed broadly through OHN listservs, social media, and to over 100 previously identified OHNs (25), with a request to distribute it beyond the OHNs. The survey link was open from 15 July 2020 to 21 August 2020.

\section{Questionnaire}

The English-only questionnaire (Supplementary Material 2) was piloted with a group of individuals from different sectors (human medicine, public health, animal health) and types of organizations (academic, non-profit), and revised to ensure clarity and consistency before its launch. The questions and response options were developed based on previous work on the topic (25) and the experience of the diverse, multidisciplinary project team (20). A definition for One Health was provided in the introduction of the survey instrument. The sixteen questions covered selected key work-related characteristics of the respondent; self-reported connection with an OHN and participation in OHN activities; self-reported involvement in COVID-19 response; skills applied and activities conducted as part of the pandemic response, if applicable; and perceived barriers and facilitators to involvement in the COVID-19 response.

As OHNs include both formal and informal structures, and in an effort toward inclusion, a definition for an OHN was not provided in this study. For purposes of this study, the sense of connection to an OHN by the survey respondent was of greatest importance, which we believed should not have been constrained by a definition.

The COVID-19 response was defined as response and/or research related to the pandemic. For categorizing the respondents by geographic regions, the WHO list of member countries and regions was applied (www.who.int/countries). For several questions, such as those concerning the type of organization and sector, the survey respondents were able 
to select multiple options from the list of possible answers, including the opportunity to select "other." Those survey respondents who were involved in a response were asked to indicate the type of work, geographic level of response, and skills and areas of expertise applied.

\section{Statistical Analyses}

We describe the data according to the background variables captured by the questionnaire. Since not all respondents answered all questions, we report the total number of respondents $(\mathrm{N})$ who answered each question.

The main results are simple distributions, presented as counts and percentages. Differences between relevant proportions were evaluated using the Chi-square test, and considered statistically significant if the 2 -sided $p$-value was $p<0.05$. The sample size we aimed for was targeted for general descriptive statistics, and subgroup analyses were not a main objective.

We report odds ratio (OR) from a logistic regression model where the outcome was the reported involvement in COVID19 response (yes/no), and dichotomous: "being part of an OHN" (yes/no) was the explanatory variable. We additionally evaluated the association with the sectors represented by at least 400 responses to the question (dichotomous variable: selected/not selected). Confounding was explored by observing any substantial change in OR after adding each of the variables, and interaction was tested for by offering an interaction term to the model. The predictive power of the logistic regression models is presented as the area under the receiver operating characteristic (ROC) curve.

Statistical tests were performed using GraphPad Prism version 6.0.1 for Windows (GraphPad Software, San Diego, California, USA; www.graphpad.com) and Stata 13.1 (StataCorp, College Station, TX, USA).

\section{Ethics Approval}

The research was exempted from ERC review by the AdHoc Covid-19 Research Ethics Review Committee (WHO ERC/Covid-19). A link to a Participant Information Sheet (PIS) was included in the survey instructions (Supplementary Material 3).

Participation was completely voluntary, no questions were mandatory to answer, and the respondents consented for their answers being used by submitting them. The data were anonymous; the dataset was checked for completeness of anonymity and de-identified (Supplementary Material 4). No potentially identifiable human data are presented in this study.

\section{RESULTS}

\section{Subject Population}

The sample for this observational study included 1,050 respondents who were categorized by three relevant work variables-location (WHO region), type of organization, and work sector (Figure 1). The respondents were from 94 countries in all six WHO regions (Figure 1A). A large proportion of survey respondents who answered the question were from the Region of the Americas (572/1,037, 55.2\%); 44.6\% (462/1,037) were from

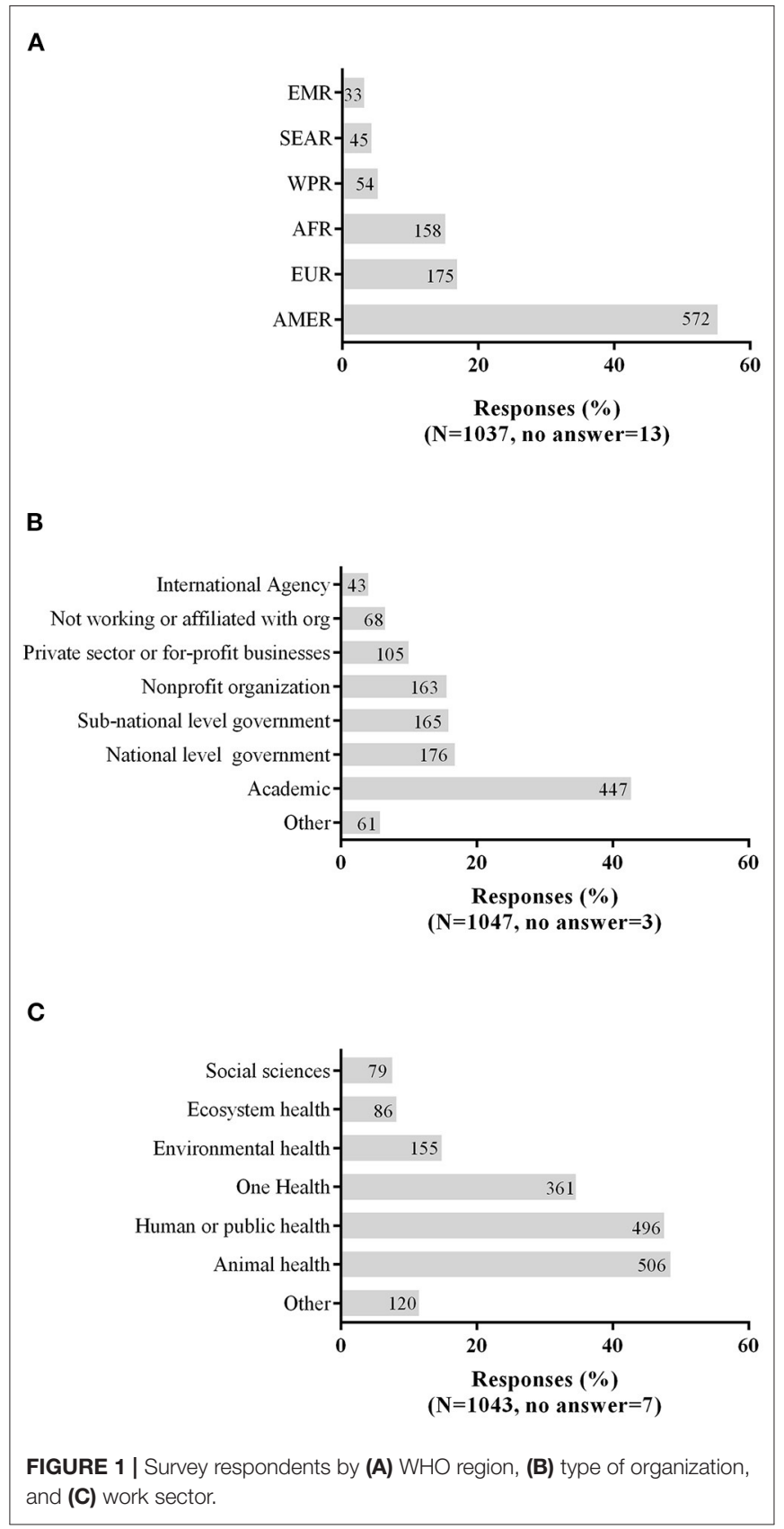

the United States. Academic organizations (Figure 1B) were the most commonly selected affiliation $(447 / 1,047,42.7 \%)$, followed by governmental organizations at the national $(176 / 1,047,16.8 \%)$ and sub-national (165/1,047, 15.8\%) levels.

The survey respondents were from a variety of work sectors (Figure 1C). A similar percentage reported working in animal health $(506 / 1,043,48.5 \%)$ and in human health or public health $(496 / 1,043,47.6 \%)$. The environmental health sector was selected by $14.9 \%(155 / 1,043)$ of respondents. Over one-third of respondents $(361 / 1,043,34.6 \%)$ self-identified as working in the One Health sector.

Overall, $13.2 \%(138 / 1,047)$ of the survey respondents indicated that they were working for or were affiliated with more 
than one type of organization (Supplementary Table 1). One Health sector respondents were more likely to report working for more than two types of organization ( $p$-value: $<0.001)$; a total of $20.8 \%(75 / 361)$ of those self-identifying as working in the One Health sector reported working for more than one type of organization, compared to $9.2 \%$ (63/686) among those working in all other sectors combined.

The majority $(299 / 361,82.8 \%)$ of respondents who reported working in One Health sector also selected at least one other sector; $50.7 \%$ (183/361) selected at least two additional sectors. This is a higher proportion compared to $18.0 \%(123 / 682)$ who reported working in more than one sector and $4.4 \%$ (30/682) who reported working in more than two sectors among those who did not identify as working in the One Health sector $(p<0.001$; Supplementary Table 1 ).

\section{Participation in One Health Networks (OHNs)}

Overall, $75.7 \%(788 / 1,041)$ of survey respondents identified as being part of an OHN. The number and percent of survey respondents, categorized by being self-described as part of an OHN, are presented by WHO region, type of organization, and work sector in Table 1. Across all WHO regions, all types of organizations, and all work sectors, the proportion of the sample reporting they were part of any $\mathrm{OHN}$ was always above $65.8 \%$. The top three $\mathrm{OHN}$ activities that most survey respondents indicated they had ever participated in were, "received communication from an OHN," "social media communications," and "OHN- hosted webinars" (Table 2). Supplementary Table 2 provides a summary of the characteristics of those respondents who indicated being part of an $\mathrm{OHN}$ compared to those who did not.

\section{Involvement in COVID-19 Response}

A total of $63.8 \%(661 / 1,036)$ of survey respondents indicated that they had been involved in COVID-19 response activities. Table 3 summarizes the answers from survey respondents who were involved in the COVID-19 response regarding the type of work, geographic level of response, and skills and areas of expertise applied. The largest percentage of the respondents (309/681, $45.4 \%$ ) indicated they were involved in education, including teaching and training. Over half the respondents indicated that their response activities were at the subnational level (364/651, $55.9 \%)$. The skills and areas of expertise applied included animal

TABLE 1 | Survey responses for being part of an OHN, involved in COVID-19 response, and both part of OHN and involved in COVID-19 response, by WHO region, type of organization, and work sector.

\begin{tabular}{|c|c|c|c|c|c|c|}
\hline & \multicolumn{2}{|c|}{ Part of OHN } & \multicolumn{2}{|c|}{$\begin{array}{c}\text { Involved in } \\
\text { CovID-19 response }\end{array}$} & \multicolumn{2}{|c|}{$\begin{array}{c}\text { Part of OHN and } \\
\text { involved in COVID-19 response }\end{array}$} \\
\hline & $n$ & $\%$ & $n$ & $\%$ & $n$ & $\%$ \\
\hline \multicolumn{7}{|l|}{ Where are you currently located? (WHO Region) } \\
\hline Americas (572) & 395 & 69.1 & 349 & 61.1 & 258 & 45.1 \\
\hline Europe (175) & 127 & 72.6 & 111 & 63.4 & 81 & 46.2 \\
\hline South-East Asia (36) & 40 & 88.9 & 30 & 66.7 & 27 & 60.0 \\
\hline Eastern Mediterranean (33) & 29 & 87.9 & 23 & 69.7 & 21 & 63.6 \\
\hline \multicolumn{7}{|c|}{ What type of organization do you currently work for or are you affiliated with?* } \\
\hline Academic (447) & 349 & 78.1 & 282 & 63.1 & 226 & 50.5 \\
\hline National level government (176) & 139 & 79.0 & 124 & 70.5 & 108 & 61.3 \\
\hline Individual not working or affiliated with organization (68) & 53 & 77.9 & 35 & 51.5 & 28 & 41.1 \\
\hline International Agency (37) & 37 & 86.0 & 35 & 81.4 & 29 & 67.4 \\
\hline Other (61) & 42 & 68.9 & 36 & 59.0 & 29 & 47.5 \\
\hline \multicolumn{7}{|l|}{ In what sector do you currently work?* } \\
\hline Animal health (506) & 402 & 79.4 & 279 & 55.1 & 227 & 44.8 \\
\hline Human or public health (496) & 383 & 77.2 & 381 & 76.8 & 302 & 60.8 \\
\hline One Health (361) & 318 & 88.1 & 257 & 71.2 & 228 & 63.1 \\
\hline Environmental health (155) & 122 & 78.7 & 107 & 69.0 & 90 & 58.0 \\
\hline Ecosystem health (86) & 76 & 88.4 & 59 & 68.6 & 55 & 63.9 \\
\hline Social sciences (79) & 60 & 75.9 & 60 & 75.9 & 50 & 63.2 \\
\hline Other (120) & 79 & 65.8 & 69 & 57.5 & 0.0 & 0.0 \\
\hline
\end{tabular}

$N$, number of people that answered the question; $n$, number of responses "Possible to select multiple options, including "other," from a list. Sum of group percentages does not $=100 \%$. 
TABLE 2 | Participation in OHN activities.

\begin{tabular}{|c|c|c|}
\hline & $n$ & $\%$ \\
\hline \multicolumn{3}{|c|}{$\begin{array}{l}\text { Please indicate if you have ever participated in these OHN activities. }{ }^{*} \\
(N=892, \text { no answer }=158)\end{array}$} \\
\hline Received communications from $\mathrm{OHN}$ list & 474 & 53.1 \\
\hline Followed OHN on social media & 379 & 42 \\
\hline Attended OHN hosted webinar & 369 & 41 \\
\hline Attended online OHN conference/meeting & 332 & 37. \\
\hline Attended in-person OHN conference/meeting & 297 & 33 \\
\hline Invited other professionals to $\mathrm{OHN}$ activities & 251 & 28 \\
\hline Used $\mathrm{OHN}$ to disseminate information & 200 & 22. \\
\hline Participated in OHN workgroup/taskforce/committee & 190 & 21. \\
\hline Participated in integrated $\mathrm{OHN}$ project & 184 & 20.6 \\
\hline Organized OHN activity & 180 & 20.2 \\
\hline Co-authored $\mathrm{OH}$ publication with $\mathrm{OHN}$ colleague & 143 & 16.0 \\
\hline Participated in $\mathrm{OHN}$ offered training & 141 & 15.8 \\
\hline Presented on $\mathrm{OH}$ topic for $\mathrm{OHN}$ & 129 & 14.5 \\
\hline
\end{tabular}

$N$, number of people that answered the question; $n$, number of responses " Possible to select multiple options, including "other," from a list. Sum of group percentages does not $=100 \%$.

health $(328 / 698,47.0 \%)$, disease surveillance $(255 / 698,36.5 \%)$, and information/knowledge management (226/698, 32.4\%).

Among the survey respondents indicating they were involved in the COVID-19 response, 79.9\% (528/661) reported being part of an OHN. Among respondents indicating they were part of an OHN, 67.2\% (528/786) were involved in COVID-19 response activities. The proportion involved in the pandemic response was smaller at 53.2\% (133/250) among those who did not identify as being part of an OHN. Being part of an OHN was positively and significantly associated with involvement in the pandemic response with a univariable odds ratio of 1.8 (95\% confidence interval: $1.348-2.405)$; the area under the ROC curve was 0.555 (Table 4).

Two univariable logistic regression models investigating the association between being from the two most commonly selected sectors and being involved in COVID-19 response activities showed that being from the animal health sector was negatively associated with involvement in the pandemic response, and being from the human health or public health sector was positively associated with involvement in the pandemic response (odds ratio $0.5,95 \%$ confidence interval: $0.382-0.639$, and odds ratio 3.1, 95\% confidence interval: 2.393-4.091, respectively). Further, two separate models including each of these two sectors as an explanatory variable alongside being part of an $\mathrm{OHN}$ as the main focus explanatory variable, supported the results of the univariable analyses, and there were no substantial changes in odds ratios. The first model showed that being from the animal health sector was negatively associated (odds ratio 0.5, 95\% confidence interval: $0.353-0.597)$ while being part of an $\mathrm{OHN}$ was positively associated (odds ratio $2.0,95 \%$ confidence interval: 1.481-2.688) with being involved in COVID-19 response; area under the ROC curve was 0.619 . The second model showed that being from the human health or public health sector was positively associated (odds ratio 3.1, 95\% confidence interval:
TABLE 3 | COVID-19 response actions by type of work and by geographic level of response, and COVID-19 response actions by skills and areas of expertise applied.

\begin{tabular}{|c|c|c|}
\hline & $n$ & $\%$ \\
\hline \multicolumn{3}{|c|}{ What is your type of work for the COVID-19 response?* } \\
\hline \multicolumn{3}{|c|}{$(N=681$, no answer $=82$, did not participate in COVID-19 response $=287)$} \\
\hline Education (teaching, presentation, training) & 309 & 45.4 \\
\hline $\begin{array}{l}\text { Practice (clinical, public health, lab } \\
\text { support, data analysis) }\end{array}$ & 264 & 38.8 \\
\hline $\begin{array}{l}\text { Writing (blog, commentary, article, other } \\
\text { publication) }\end{array}$ & 187 & 27.5 \\
\hline Health policy and consultation & 173 & 25.4 \\
\hline Research (basic, clinical, operational) & 138 & 20.3 \\
\hline Administration and support & 130 & 19.1 \\
\hline Research (social science, fieldwork) & 127 & 18.6 \\
\hline $\begin{array}{l}\text { Research (COVID-19 diagnostics, } \\
\text { treatments, or vaccines) }\end{array}$ & 90 & 13.2 \\
\hline Other & 98 & 14.4 \\
\hline
\end{tabular}

At what level is your COVID-19 response and/or research activities?*

$(N=651$, no answer $=89$, did not participate in COVID-19 response $=310)$

Subnational-local, district, state $\quad 364 \quad 55.9$

National-in one country $\quad 301 \quad 46.2$

International-in multiple countries $\quad 144 \quad 22.1$

$\begin{array}{lll}\text { Other } & 0.0 & 0.0\end{array}$

What skills/areas of expertise have you applied to the COVID-19 response?*

$(N=698$, no answer $=81$, did not participate in COVID-19 response $=271)$

Animal health $\quad 328 \quad 47.0$

Disease surveillance $\quad 255 \quad 36.5$

Information/knowledge management $\quad 226 \quad 32.4$

$\begin{array}{lll}\text { Communications and media } & 220 & 31.5\end{array}$

$\begin{array}{lll}\text { Community engagement } & 180 & 25.8\end{array}$

Risk assessment and management $\quad 172 \quad 24.6$

$\begin{array}{lll}\text { Risk communications } & 162 & 23.2\end{array}$

Infection and Prevention Control (IPC) $\quad 160 \quad 22.9$

Outbreak or epidemiological research $\quad 150 \quad 21.5$

Data management $\quad 136 \quad 19.5$

Environmental health $\quad 123 \quad 17.6$

Basic research on coronavirus $\quad 114 \quad 16.3$

Laboratory support and diagnostics $\quad 112 \quad 16$

$\begin{array}{lll}\text { Contact tracing } & 111 & 15.9\end{array}$

$\begin{array}{lll}\text { Social sciences } & 88 & 12.6\end{array}$

$\begin{array}{lll}\text { Logistics/supply chain } & 68 & 9.7\end{array}$

$\begin{array}{lll}\text { Case management } & 64 & 9.2\end{array}$

$\begin{array}{lll}\text { Testing and diagnostics development } & 56 & 8.0\end{array}$

$\begin{array}{lll}\text { Human clinical care } & 52 & 7.4\end{array}$

$\begin{array}{lll}\text { Operational research } & 51 & 7.3\end{array}$

$\begin{array}{lll}\text { Clinical research } & 50 & 7.2\end{array}$

Vaccine development $\quad 19 \quad 2.7$

$\begin{array}{lll}\text { Other } & 59 & 8.5\end{array}$

$N$, number of people that answered the question; $n$, number of responses. "Possible to select multiple options, including "other," from a list. Sum of group percentages does not $=100 \%$.

2.381-4.094) and being part of an $\mathrm{OHN}$ was positively associated (odds ratio 1.8, 95\% confidence interval: 1.318-2.406) with being 
TABLE 4 | Contingency table showing the association (odds ratio: 1.8, 95\% confidence interval: 1.3-2.4, Chi-square: 16.04) between being part of an $\mathrm{OHN}$ and being involved in the COVID-19 response.

\begin{tabular}{lcccc}
\hline & $\begin{array}{c}\text { Involved in } \\
\text { COVID-19 } \\
\text { response }\end{array}$ & $\begin{array}{c}\text { Not involved } \\
\text { in COVID-19 } \\
\text { response }\end{array}$ & $\begin{array}{c}\text { No answer } \\
\text { for COVID-19 } \\
\text { response }\end{array}$ & Totals \\
\hline Part of OHN & 528 & 258 & 2 & 788 \\
Not part of OHN & 133 & 117 & 3 & 253 \\
No answer for OHN & 2 & 3 & 4 & 9 \\
Totals & 663 & 378 & 9 & 1,050 \\
\hline
\end{tabular}

involved in COVID-19 response; area under the ROC curve was 0.663 . No interaction was evident between either of the sets of two explanatory variables. The sample size did not allow a similar analysis of the environmental sector.

\section{Barriers and Facilitators to Involvement in COVID-19 Response}

Overall, $38.3 \%(387 / 1,011)$ of survey respondents reported no perceived barriers to their participation in COVID-19 response activities. The most frequently reported barrier was "no financial support" (248/1,011, 24.5\%), followed by "lack of opportunity or path for involvement" (211/1,011, 20.9\%). Personal and organizational interest were the greatest facilitators for involvement (Table 5).

Figure 2 presents the perceived barriers to involvement in the COVID-19 response for the WHO regions that were represented by at least 100 responses to the question, notably the European, African, and Americas regions. Barriers perceived by survey respondents from the European and Americas regions were generally similar to one another. The most frequently reported barrier by respondents from the African region was "lack of financial support" (66/158, 41.8\%). The proportion selecting this as a barrier was significantly lower in the other two regions: $19.4 \%(34 / 175)$ in the European region and $17.8 \%(102 / 572)$ in the Americas $(p<0.001)$. A significantly lower percentage of respondents from the African region indicated not knowing how to get involved $(13 / 158,8.2 \%)$, compared to respondents from the Americas (84/572, 14.7\%; $p<0.05)$.

\section{Perceived Usefulness of OHNs During COVID-19 Response}

While $43.6 \%$ (235/539) of the survey respondents who affiliated with an OHN that contributed to the COVID-19 response found OHNs very helpful or extremely helpful, 19.1\% (103/539) found OHNs to be of little or no help (Supplementary Figure 1). The $\mathrm{OHN}$ offerings most frequently reported as especially useful were "increasing public awareness of the value of One Health" $(712 / 923,77.1 \%)$ and "networking with professionals across sectors with common interests” (517/923, 56.0\%; Table 6).

\section{DISCUSSION}

One Health has been invoked on the international stage as a major principle with which to fight the COVID-19 pandemic
TABLE 5 | Barriers and facilitators to participation in COVID-19 response activities.

n $\quad \%$

\begin{tabular}{lcc}
\hline $\begin{array}{l}\text { Barriers to participation in COVID-19 response } \\
\text { answer }=\mathbf{3 9} \text { ) }\end{array}$ & $\mathbf{N}=\mathbf{1 , 0 1 1}, \mathbf{n o}$ \\
$\begin{array}{l}\text { There were no barriers to my } \\
\text { participation }\end{array}$ & 387 & 38.3 \\
No financial support & 248 & 24.5 \\
No opportunity or path for & 211 & 20.9 \\
involvement & 172 & 17.0 \\
Not part of my job & 149 & 14.7 \\
No time & 143 & 14.1 \\
Don't know how to get involved & 94 & 9.3 \\
Lack of organizational interest & 24 & 2.4 \\
Lack of personal interest & 123 & 12.2 \\
Other &
\end{tabular}

Facilitators to participation in COVID-19 response* $(N=1,015$, no answer $=35$, did not participate in COVID-19 response $=295$ )

$\begin{array}{lll}\text { Personal interest } & 508 & 50.1\end{array}$

$\begin{array}{lll}\text { Organizational interest } & 391 & 38.5\end{array}$

I have not participated in COVID-19 $295 \quad 29.1$

response and/or research

$\begin{array}{lll}\text { Part of established duties at my } & 295 & 29.1\end{array}$

current job

$\begin{array}{lll}\text { Part of a new project/special } & 223 & 22.0\end{array}$

deployment for COVID-19

Availability of new COVID-19 funding $\quad 124 \quad 12.2$

I learned of volunteer opportunity $\quad 42 \quad 4.1$

through $\mathrm{OHN}$

I learned of job opportunity through

$\mathrm{OHN}$

$\begin{array}{ll}21 & 2.1 \\ 59 & 5.8\end{array}$

$N$, number of people that answered the question; $n$, number of responses. " $P$ ossible to select multiple options, including "other", from a list. Sum of group percentages does not $=100 \%$.

and to prevent future pandemics. This study describes the contributions of a cross section of the global One Health community that included a broad representation that spanned geographic regions, organizations, and work sectors in the early stages of the COVID-19 pandemic. It captures what individuals regarded as barriers and facilitators to their involvement, including the role of participating in an $\mathrm{OHN}$, and reveals where further research is warranted.

Being part of an $\mathrm{OHN}$ was positively associated with involvement in COVID-19 responses. This provides evidence for the value of OHNs for workforce capacity building. However, not all respondents found OHNs helpful. For those survey participants who were part of an $\mathrm{OHN}$, this could be interpreted as indication of a need for OHNs to better align their activities with workforce priorities and to consider and measure perceived value for those activities. Our finding that those who were part of an $\mathrm{OHN}$ were almost two times more likely to be involved in the COVID-19 response may indicate greater awareness and access to opportunities through an OHN connection. Further research is needed to fully explore critical areas for intervention and how OHNs can be a vehicle to support a global outbreak response workforce. 


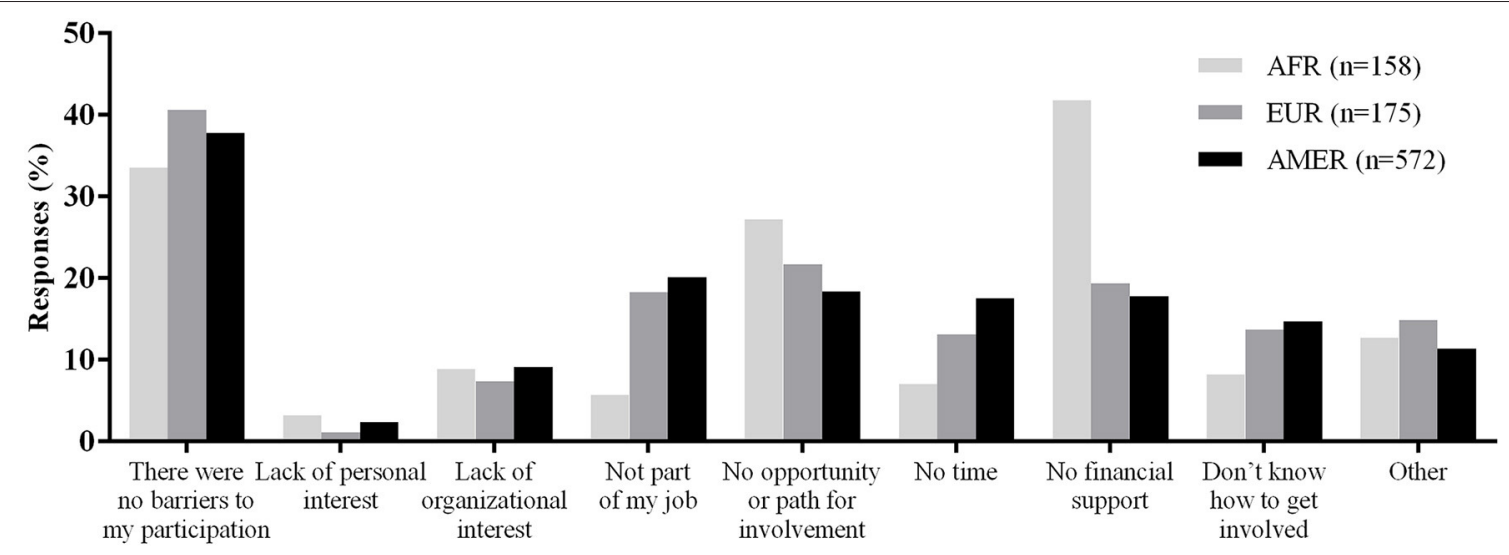

FIGURE 2 | Perceived barriers to participation in COVID-19 response by WHO region.

TABLE 6 | Perceived usefulness of OHN activities during the COVID-19 response.

What $\mathrm{OHN}$ offerings do you think are especially useful during the COVID-19 response?*

$(N=923$, no answer $=127)$

Increased public awareness of the value of

$\mathrm{OH}$

Networking with professionals across

sectors with common interests

Trusted information about the COVID-19

pandemic

Links to popular media items relevant to

$\mathrm{OH}$ and current events

Targeted training opportunities

Information about professional, career, and service opportunities

Opportunities to contribute in ways that

my employment does not provide

Other

712

517

466

338

335

310

269

33

$N$, number of people that answered the question; $n$, number of responses. "Possible to select all that apply from list of options, including "other." Sum of percentages does not $=100 \%$.

In this study, many respondents were affiliated with academic organizations, which may reflect some of the criticism that the One Health concept remains an academic exercise with little practical operationalization (38, 39). However, a substantial proportion of the survey respondents were affiliated with governmental organizations, highlighting channels toward greater operationalization of One Health. These results can inform sampling designs that ensure greater responses from multiple stakeholder groups, including the public sector, development institutions, and non-governmental organizations (NGOs).

The similar proportion of respondents in our study from human or public health and animal health sectors indicated a balance in input from key professional arenas within the global One Health community. A smaller proportion of respondents identified as being from the environmental sector, the third classical pillar of One Health. This may be a shortcoming in the reach of the survey dissemination to those working in environmental and ecosystem health. Indeed, limited representation of the environmental sector is often noticed in One Health initiatives with calls for better engagement (25, 40). Additionally, with growing awareness of the importance of the social drivers of disease, a specific area for public health strengthening is the integration of social science perspectives into One Health $(41,42)$. Our study sample included a relatively small proportion of respondents from the social science sector. The results of this study can help in planning sampling for future studies and targeted approaches for reaching out to underrepresented fields.

The survey respondents who were involved with the COVID19 response reported various types of work, geographic level of response, and skills and areas of expertise applied. Further studies are needed to investigate other aspects of worker pandemic response activities, such as the extent of involvement in terms of time used or proportion of working time allocated. Furthermore, knowing the impact of other multisectoral workforce involvement outside of OHNs would be useful to ascertain lessons learned from this pandemic.

The survey respondents reported a number of barriers that hindered involvement in COVID-19 response activities, although the reason for the barriers was beyond the scope of this study and merits further investigation. These results highlight opportunities for regional OHNs, as well as other actors, to find tailored solutions to enable involvement and activation of professional expertise. This might include enhanced dissemination of relevant opportunities, as exemplified by the joint GOARN call to action (28), paths for involvement for experts across the fields, and targeted funding programs for OHN support.

One barrier to involvement in COVID-19 response activities reported was lack of opportunities or paths for involvement, which can be addressed at the local, national, regional, and international levels. There is room for improvement in the extent to which One Health is taught and embraced in professional education across sectors with calls for the structured incorporation of One Health into professional degree programs 
(24). OHNs are well-positioned to provide the targeted One Health professional development, continuing education, and workforce training needed. The USAID One Health Workforce Next Generation Project, for example, is specifically building the capacity of OHNs worldwide to prevent, detect, and respond to COVID-19 and other infectious diseases (43). A deeper analysis of the barriers and facilitators, matched with strategies to address them, could help to inform local, national, and global initiatives to guide workforce policy and management in light of what we have learned from COVID-19 $(37,44)$.

This study had some relevant limitations. A major one was bias due to the dissemination routes and snowball sampling method, which oversampled the One Health community and possibly also those involved in COVID-19 response activities. While the geographical distribution of the respondents reflected the global reach of OHN networks, it also revealed shortcomings in the recruiting of survey participants. These results, however, highlight where OHNs need to focus attention for inclusion by, for example, addressing language barriers or other obstacles to participation in the study and by better coordination across $\mathrm{OHNs}$ to expand reach and leverage resources.

Collider bias also could have affected our results and limited the ability to make comparisons between those who reported being part of an $\mathrm{OHN}$ and those who did not. Other limitations included an English-only questionnaire, self-reporting, and general constraints of questionnaire studies. For example, despite careful design and piloting, some concepts in the questions may have been understood differently by some respondents. Free text responses might have also provided different results for some of the questions beyond the options provided. Importantly, the concept of "OHN" was not defined in this work. Moreover, lack of sociodemographic data was a limitation. Future studies should include variables, such as age, ethnicity, gender, and career stage to evaluate the presence of selection and response bias, as well as any confounding variables. This would also provide insight into any disparities observed based on these sociodemographic variables as a first step to addressing them.

Operationalizing One Health will need to be adapted to build the workforce competencies required for the post-COVID-19 future. Despite the proven benefit of One Health approaches during pandemics (14), the establishment of an effective multisectoral workforce remains problematic. This is due, in part, to the lack of integration of the One Health approach into current international treaties (45). For example, shortcomings in including the One Health approach in the International Health Regulations (IHR) have been linked to delayed and suboptimal action during the early response to $\operatorname{COVID-19}(36,45)$. Calls for global governance and financing mechanisms to advance One Health as a guiding principle to reform global public health are key to actionable system-level solutions to scale up pandemic preparedness, including workforce development (46). Greater understanding of the activities and needs of the One Health workforce during a pandemic response helps to pave the way for meaningful integration into coordinated and shared strategies for preventing, detecting, and responding to global public health emergencies.

\section{DATA AVAILABILITY STATEMENT}

The coded dataset of de-identified survey responses used in this study is included as Supplementary Material. Further inquiries can be directed to the corresponding author.

\section{ETHICS STATEMENT}

The research was exempted from ERC review by the AdHoc Covid-19 Research Ethics Review Committee (WHO ERC/Covid-19). Participation was completely voluntary, no questions were mandatory to answer, and the respondents consented for their answers being used by submitting them. The data were anonymous; the dataset was checked for completeness of anonymity and de-identified. No potentially identifiable human data are presented in this study.

\section{AUTHOR CONTRIBUTIONS}

LSt, VD, and CS conceptualized the study. LSt and CS verified the underlying data and had access to all data. LSe ran the statistical analyses and created the figures. PJ, JB, LSt, and VD contributed to the data analysis. LSt prepared the first manuscript draft. All authors participated in the design of the study, had access to the de-identified dataset, participated in interpretation of the results, contributed to writing and editing the paper, and approved the final manuscript for publication.

\section{FUNDING}

This work was supported by the One Health Commission and the European Union Horizon 2020 Research and Innovation Program under grant agreement number 773830: One Health European Joint Programme. The European Union Horizon 2020 Research and Innovation Program provided funds for the open access publication fee. The funders had no role in the study design, data collection, data analysis, data interpretation, or writing the manuscript.

\section{ACKNOWLEDGMENTS}

We thank all the survey respondents and everyone who helped to distribute the survey link. Dr. John Lamb provided helpful comments on the manuscript. PJ and LSe are part of the One Health European Joint Programme consortium. Selected preliminary results of this study have been presented at the 8th International Meeting on Emerging Diseases and Surveillance, IMED 2021, and at the Annual Scientific Meeting of the One Health European Joint Programme, OHEJP ASM 2021.

\section{SUPPLEMENTARY MATERIAL}

The Supplementary Material for this article can be found online at: https://www.frontiersin.org/articles/10.3389/fpubh. 2022.830893/full\#supplementary-material 


\section{REFERENCES}

1. Pak A, Adegboye OA, Adekunle AI, Rahman KM, McBryde ES, Eisen DP. Economic consequences of the COVID-19 outbreak: the need for epidemic preparedness. Front Public Health. (2020) 8:241. doi: 10.3389/fpubh.2020.00241

2. Nicola M, Alsafi Z, Sohrabi C, Kerwan A, Al-Jabir A, Iosifidis C, et al. The socio-economic implications of the coronavirus pandemic (COVID-19): a review. Int J Surg. (2020) 78:185-93. doi: 10.1016/j.ijsu.2020.04.018

3. United Nations Environment Programme. Joint Tripartite and UNEP Statement on Definition of One Health. (2021). Available online at: https:// wedocs.unep.org/bitstream/handle/20.500.11822/37600/JTFOWU.pdf (accessed January 9, 2022).

4. Mahdy MAA, Younis W, Ewaida Z. An overview of SARS-CoV-2 and animal infection. Front Vet Sci. (2020) 7:596391. doi: 10.3389/fvets.2020.596391

5. World Health Organization. WHO-Convened Global Study of Origins of SARSCoV-2: China Part. (Joint WHO-China Study Joint Report 14 January-10 February 2021 (2021). Available online at: https://www.who.int/health-topics/ coronavirus/origins-of-the-virus (accessed April 1, 2021).

6. Larsen HD, Fonager J, Lomholt FK, Dalby T, Benedetti G, Kristensen B, et al. Preliminary report of an outbreak of SARS-CoV-2 in mink and mink farmers associated with community spread, Denmark, June to November (2020). Euro Surveill. (2021) 26:2100009. doi: 10.2807/1560-7917.ES.2021.26.5.210009

7. World Health Organization, Food and Agriculture Organization of the United Nations, International Office of Epizootics. Taking a Multisectoral, One Health Approach: A Tripartite Guide to Addressing Zoonotic Diseases in Countries. (2019). Available online at: https://apps.who.int/iris/handle/10665/ 325620 (accessed April 10, 2021).

8. United Nations Environment Programme. One Health'Approach Critical to Tackle Health Inequality and Emerging Diseases. (2021). Available online at: https://www.unep.org/news-and-stories/story/one-health-approachcritical-tackle-health-inequality-and-emerging-diseases (accessed January 9 , 2022).

9. Berthe F, Bouley TA, Karesh WB, Legall IC, Machalaba CC, Plante CA, et al. One Health: Operational Framework for Strengthening Human, Animal, and Environmental Public Health Systems at Their Interface (English). Washington, DC: World Bank Group (2018). Available online at: http://documents.worldbank.org/curated/en/961101524657708673/Onehealth-operational-framework-for-strengthening

10. Van Nieuwkoop M. Staying Focused on "One Health" to Prevent the Next Pandemic. World Bank Blogs (2020). Available online at: https://blogs. worldbank.org/voices/staying-focused-one-health-prevent-next-pandemic (accessed March 15, 2021).

11. The World Bank. Safeguarding Animal, Human and Ecosystem Health: One Health at the World Bank. (2021). Available online at: https://www.worldbank. org/en/topic/agriculture/brief/safeguarding-animal-human-and-ecosystemhealth-one-health-at-the-world-bank (accessed January 10, 2022).

12. Deem SL, Brenn-White M. One Health-the key to preventing COVID-19 from becoming the new normal. Mol Front J. (2020) 4:30-5. doi: 10.1142/S2529732520400039

13. Kelly TR, Karesh WB, Johnson CK, Gilardi KVK, Anthony SJ, Goldstein T, et al. One Health proof of concept: bringing a transdisciplinary approach to surveillance for zoonotic viruses at the human-wild animal interface. Prev Vet Med. (2017) 137:112-8. doi: 10.1016/j.prevetmed.2016.11.023

14. Ruckert A, Zinszer K, Zarowsky C, Labonté R, Carabin H. What role for One Health in the COVID-19 pandemic? Can J Public Health. (2020) 111:6414. doi: 10.17269/s41997-020-00409-z

15. Humboldt-Dachroeden S, Rubin O, Sylvester Frid-Nielsen S. The state of One Health research across disciplines and sectors - a bibliometric analysis. One Health. (2020) 10:100146. doi: 10.1016/j.onehlt.2020.100146

16. Zumla A, Dar O, Kock R, Muturi M, Ntoumi F, Kaleebu P, et al. Taking forward a "One Health" approach for turning the tide against the Middle East respiratory syndrome coronavirus and other zoonotic pathogens with epidemic potential. Int J Infect Dis. (2016) 47:59. doi: 10.1016/j.ijid.2016.06.012

17. Conrad PA, Meek LA, Dumit J. Operationalizing a One Health approach to global health challenges. Comp Immunol Microbiol Infect Dis. (2013) 36:211-6. doi: 10.1016/j.cimid.2013.03.006
18. Häsler B, Bazeyo W, Byrne AW, Hernandez-Jover M, More SJ, Rüegg SR, et al. Reflecting on One Health in action during the COVID-19 response. Front Vet Sci. (2020) 7:578649. doi: 10.3389/fvets.2020.578649

19. Steele SG, Toribio J-ALML, Mor SM. Global health security must embrace a One Health approach: contributions and experiences of veterinarians during the COVID-19 response in Australia. One Health. (2021) 13:100314. doi: 10.1016/j.onehlt.2021.100314

20. Berezowski J, Akkina J, Del Rio Vilas VJ, DeVore K, Dorea FC, Dupuy C, et al. One Health Surveillance: perceived benefits and workforce motivations. Rev Sci Tech. (2019) 38:251-60. doi: 10.20506/rst.38.1.2957

21. Frankson R, Hueston W, Christian K, Olson D, Lee M, Valeri L, et al. One health core competency domains. Front Public Health. (2016) 4:192. doi: 10.3389/fpubh.2016.00192

22. Larsen RJ. Shared curricula and competencies in One Health and Health Professions Education. Med Sci Educ. (2020) 31:24952. doi: 10.1007/s40670-020-01140-7

23. Moradian N, Ochs HD, Sedikies C, Hamblin MR, Camargo CA, Martinez JA, et al. The urgent need for integrated science to fight COVID-19 pandemic and beyond. J Transl Med. (2020) 18:205. doi: 10.1186/s12967-020-02364-2

24. Roopnarine R, Boeren E, Regan J-A. The missing professional perspective: medical, veterinary, and dual degree public health student perceptions of One Health. Front Public Health. (2021) 9:704791. doi: 10.3389/fpubh.2021.7 04791

25. Khan MS, Rothman-Ostrow P, Spencer J, Hasan N, Sabirovic M, RahmanShepherd A, et al. The growth and strategic functioning of One Health networks: a systematic analysis. Lancet Planet Health. (2018) 2:e26473. doi: 10.1016/S2542-5196(18)30084-6

26. Brown HL, Passey JL, Getino M, Pursley I, Basu P, Horton DL, et al. The One Health European Joint Programme (OHEJP), 2018-2022: an exemplary One Health initiative. J Med Microbiol. (2020) 69:10379. doi: 10.1099/jmm.0.001228

27. Keune H, Flandroy L, Thys S, De Regge N, Mori M, Antoine-Moussiaux N, et al. The need for European OneHealth/EcoHealth networks. Arch Public Health. (2017) 75:64. doi: 10.1186/s13690-017-0232-6

28. One Health Commission. COVID-19 Call to the Global One Health Community: Short-Term Assignments with the WHO Global Outbreak Alert and Response Network (GOARN). (2020). Available online at: https:// www.onehealthcommission.org/index.cfm/3805048654/covid19_call_to_ the_global_one_health_commnity_shortterm_assignments_with_the_who_ global_outbreak_alert_and_response_network_goarn (accessed January 10, 2022).

29. Rüegg SR, Nielsen LR, Buttigieg SC, Santa M, Aragrande M, Canali M, et al. A systems approach to evaluate One Health initiatives. Front Vet Sci. (2018) 5:23. doi: $10.3389 /$ fvets.2018.00023

30. Baum SE, Machalaba C, Daszak P, Salerno RH, Karesh WB. Evaluating One Health: are we demonstrating effectiveness? One Health. (2017) 3:510. doi: 10.1016/j.onehlt.2016.10.004

31. Bordier M, Delavenne C, Nguyen DTT, Goutard FL, Hendrikx P. One health surveillance: a matrix to evaluate multisectoral collaboration. Front Vet Sci. (2019) 6:109. doi: 10.3389/fvets.2019.00109

32. Pelican K, Salyer SJ, Barton Behravesh C, Belot G, Carron M, Caya F, et al. Synergising tools for capacity assessment and One Health operationalisation. Rev Sci Tech. (2019) 38:71-89. doi: 10.20506/rst.38.1.2942

33. Errecaborde KM, Macy KW, Pekol A, Perez S, O’Brien MK, Allen I, et al. Factors that enable effective One Health collaborations - a scoping review of the literature. PLOS ONE. (2019) 14:e0224660. doi: 10.1371/journal.pone.0224660

34. Errecaborde KM, Rist C, Travis DA, Ragan V, Potter T, Pekol A, et al. Evaluating One Health: the role of team science in multisectoral collaboration. Rev Sci Tech. (2019) 38:279-89. doi: 10.20506/rst.38.1.2960

35. von Elm E, Altman DG, Egger M, Pocock SJ, Gøtzsche PC, Vandenbroucke JP, et al. The Strengthening the Reporting of Observational Studies in Epidemiology (STROBE) statement: guidelines for reporting observational studies. Lancet. (2007) 370:1453-7. doi: 10.1016/S0140-6736(07)61602-X

36. De La Rocque S, Caya F, El Idrissi AH, Mumford L, Belot G, Carron M, et al. One Health operations: a critical component in the International Health Regulations Monitoring and Evaluation Framework. Rev Sci Tech. (2019) 38:303-14. doi: 10.20506/rst.38.1.2962 
37. Singh S, McNab C, Olson RM, Bristol N, Nolan C, Bergstrøm E, et al. How an outbreak became a pandemic: a chronological analysis of crucial junctures and international obligations in the early months of the COVID-19 pandemic. Lancet. (2021) 398:2109-24. doi: 10.1016/S0140-6736(21)01897-3

38. de Garine-Wichatitsky M, Binot A, Morand S, Kock R, Roger F, Wilcox BA, et al. Will the COVID-19 crisis trigger a One Health coming-of-age? Lancet Planet Health. (2020) 4:e377-8. doi: 10.1016/S2542-5196(20)30179-0

39. Hitziger M, Esposito R, Canali M, Aragrande M, Häsler B, Rüegg SR. Knowledge integration in One Health policy formulation, implementation and evaluation. Bull World Health Organ. (2018) 96:211-8. doi: 10.2471/BLT.17.202705

40. Essack SY. Environment: the neglected component of the One Health triad. Lancet Planet Health. (2018) 2:e238-9. doi: 10.1016/S2542-5196(18)3 0124-4

41. Bardosh KL, de Vries DH, Abramowitz S, Thorlie A, Cremers L, Kinsman $\mathrm{J}$, et al. Integrating the social sciences in epidemic preparedness and response: a strategic framework to strengthen capacities and improve Global Health security. Global Health. (2020) 16:120. doi: 10.1186/s12992-020-00 652-6

42. Woldehanna S, Zimicki S. An expanded One Health model: integrating social science and One Health to inform study of the human-animal interface. Soc Sci Med. (2015) 129:87-95. doi: 10.1016/j.socscimed.2014.10.059

43. One Health Workforce-Next Generation Consortium. 2021 Semiannual Report. One Health Institute, University of California, Davis, CA (2021). Available online at: https://ohi.vetmed.ucdavis.edu/sites/g/files/ dgvnsk5251/files/inline-files/OHW-NG_SAR_Year2_Final_2021-06-29 \%20-\%20COMPRESSED.pdf (accessed January 10, 2022).

44. World Health Organization. Health Workforce Policy and Management in the Context of the COVID-19 Pandemic Response: Interim Guidance. Report No.: WHO/2019-nCoV/health_workforce/2020.1 (2020). Available online at: WHO-2019-nCoV-health_workforce-2020.1-eng.pdf (accessed April 20, 2021).

45. Ruckert A, Goncalo das Neves C, Amuasi J, Hindmarch S, Brux C, Winkler AS, et al. One Health as a Pillar for a Transformative Pandemic Treaty. Global Health Centre (2021). Available online at: https://www.graduateinstitute.ch/ sites/internet/files/2021-11/policybrief-onehealth-v3.pdf

46. G20 High Level Independent Panel on, Financing the Global Commons for, Pandemic Preparedness and Response. A Global Deal for Our Pandemic Age. (2021). Available online at: https://pandemic-financing.org/report/ (accessed January 12, 2022).

Conflict of Interest: The authors declare that the research was conducted in the absence of any commercial or financial relationships that could be construed as a potential conflict of interest.

Publisher's Note: All claims expressed in this article are solely those of the authors and do not necessarily represent those of their affiliated organizations, or those of the publisher, the editors and the reviewers. Any product that may be evaluated in this article, or claim that may be made by its manufacturer, is not guaranteed or endorsed by the publisher.

Copyright (C) 2022 Streichert, Sepe, Jokelainen, Stroud, Berezowski and Del Rio Vilas. This is an open-access article distributed under the terms of the Creative Commons Attribution License (CC BY). The use, distribution or reproduction in other forums is permitted, provided the original author(s) and the copyright owner(s) are credited and that the original publication in this journal is cited, in accordance with accepted academic practice. No use, distribution or reproduction is permitted which does not comply with these terms. 